\title{
Response Modulation in the Zebra Finch Neostriatum: Relationship to Nuclear Gene Regulation
}

\author{
Roy Stripling, ${ }^{1}$ Susan F. Volman, ${ }^{2}$ and David F. Clayton ${ }^{1}$ \\ ${ }^{1}$ Beckman Institute Neural Pattern Analysis, Group, Neuroscience Program and Department of Cell and Structural \\ Biology, University of Illinois, Urbana, Illinois 61801 and ${ }^{2}$ Department of Zoology and Graduate Program in Neuroscience, \\ Ohio State University, Columbus, Ohio 43210
}

\begin{abstract}
The sound of birdsong activates robust gene expression in the caudomedial neostriatum (NCM) of songbirds. To assess the function of this genomic response, we analyzed the temporal and quantitative relationships between electrophysiological activity and gene induction. Single units in zebra finch NCM showed large increases in firing in response to birdsong, whereas simple auditory tones tended to inhibit firing. Most cells showed little selectivity for individual songs based on total number of spikes produced. When a novel song stimulus was repeated, the cells rapidly modulated their firing rates so that the first response to a stimulus was markedly higher than consecutive responses. Even after many repetitions of a particular song, cells continued to fire in response to that stimulus, unlike the complete "habituation" observed previously for genomic activity. The initial modulation of the response to a
\end{abstract}

particular song disappeared, however, once that song was repeated for 200 trials ( $\sim 34 \mathrm{~min})$. These results indicate a dissociation between gross physiological activity and "immediate early" gene expression: genomic activity occurs only during a subset of electrophysiological responses. We propose a model in which nuclear responses in NCM are modulated by pathways distinct from the primary auditory inputs to NCM. This would account for the changing selectivity of the genomic response and implies an active role for the cell nucleus as an integrating agent in the physiological operation of neural circuits.

Key words: zebra finch; songbird; neostriatum; NCM; ZENK; immediate early gene; auditory; single-unit recording; modulation; adaptation; habituation
The sound of birdsong activates gene transcription in cells of the caudomedial neostriatum (NCM) of songbirds (Mello et al., 1992; Nastiuk et al., 1994). The gene response to a particular song is extinguished by stimulus repetition, yet subsequent presentation of a novel song will reactivate transcription in the same neurons (Mello et al., 1995). These observations raise two questions of general interest. First, what is the physiological function of NCM? The neural basis for song communication in birds has been a subject of intensive study, and this has led to the description of a circuit responsible for song production (Nottebohm et al., 1976; Konishi, 1989). NCM is distinct from the established song control circuit, however, and no specific role for it in song biology has been defined (Mello and Clayton, 1994). Second, what is the physiological function of the genomic response to novel song? Much evidence indicates a necessary role for gene expression in the consolidation of memories (Davis and Squire, 1984; Goelet et al., 1986), and gene induction in NCM could be related to some aspect of memory storage.

The simplest model that would account for both the function of NCM and the function of the gene response to novel song is as follows. Firing in NCM would be driven by inputs from lower auditory centers, consistent with the anatomical location of NCM

Received Nov. 5, 1996; revised Jan. 27, 1997; accepted Feb. 27, 1997.

This research was supported by National Institutes of Health grants to D.F.C. (MH52086) and S.F.V. (MH47330). We thank Albert Feng for help in initiating these electrophysiological studies, Mark Nelson for useful discussions, Kris Schuett for technical assistance, and Joseph Malpeli and Amy Kruse for critical reading of this manuscript.

Correspondence should be addressed to Dr. David F. Clayton, Beckman Institute, Neural Pattern Analysis, 405 North Matthews Street, Urbana, IL 61801.

Copyright (C) 1997 Society for Neuroscience 0270-6474/97/173883-11\$05.00/0 just distal to the primary auditory telencephalon (Mello and Clayton, 1994; Vates et al., 1996). Repeated activation of particular synapses onto NCM would lead to their attentuation, via mechanisms of short-term memory storage (e.g., phosphorylation of postsynaptic receptors). The function of the gene response would be to consolidate these initial changes, by supporting more lasting structural changes in the attenuated synapses. As a result, the neurons would eventually cease firing in response to the repeated stimulus, and the genomic response would also cease. This model would be consistent with a role for NCM as a storehouse for memories of specific songs.

The goal of the present study was to test specific predictions of this simple model. First, if NCM neurons are storing song memories, then neurons in adult birds should show some selectivity in their electrophysiological response to specific songs or song elements. Second, if the "habituation" of the gene response is attributable to attenuation of specific synaptic inputs, then the production of action potentials by NCM neurons should decrease and perhaps even cease when a single song is repeated. To test these predictions, we recorded electrophysiological activity in single units within NCM during the presentation of songs and other auditory stimuli. Our results are incompatible with the simplest functional model just outlined, and we propose an alternative model to account for the function of NCM and the significance of the changing gene response to song.

Some of these results have been published previously in abstract form (Stripling et al., 1994, 1995).

\section{MATERIALS AND METHODS}

Use of awake, restrained birds. Two considerations made it essential to perform the electrophysiological experiments in awake, unanesthetized 


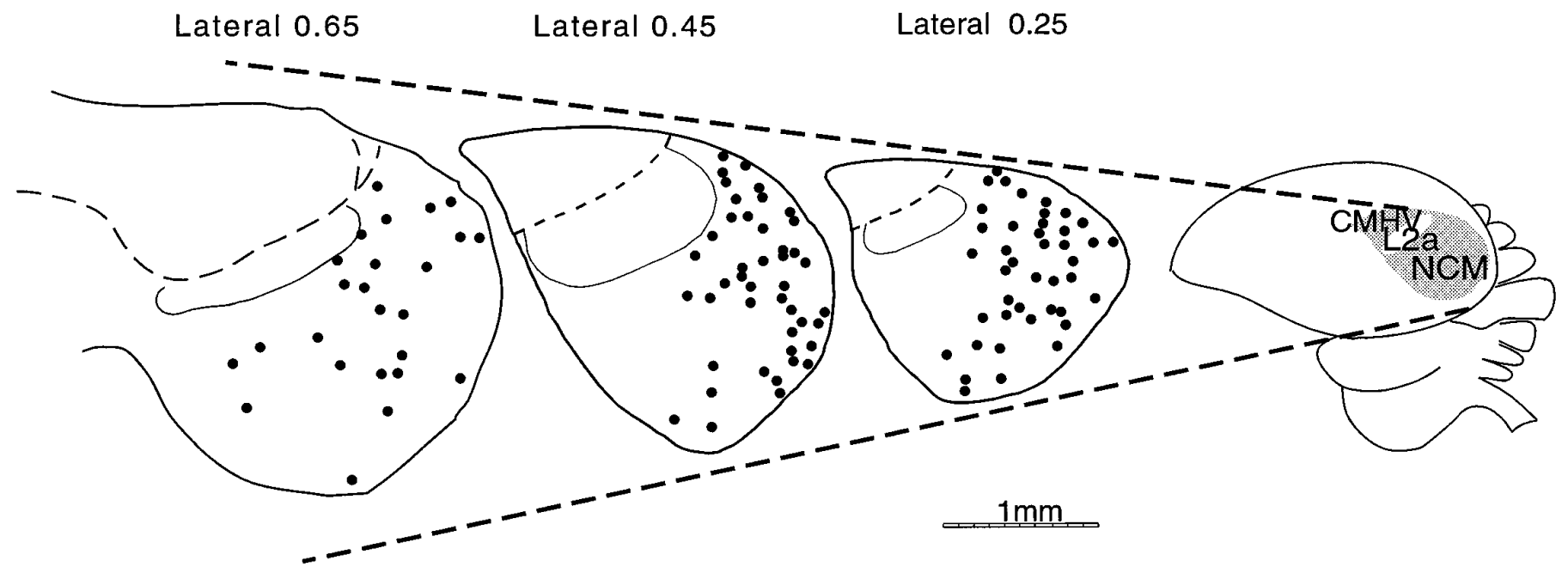

Figure 1. Camera lucida drawings of sagittal sections showing the locations of the single units recorded in NCM. The shaded area on the rightmost section indicates the region of greatest zenk response after song stimulation as described previously (Mello and Clayton, 1994). Recording sites were mapped as described in Materials and Methods. All recording sites were between $0.21 \mathrm{~mm}$ and $0.78 \mathrm{~mm}$ to the left of the midline and have been projected onto the nearest of the three representative sections shown at $0.25,0.45$, and $0.65 \mathrm{~mm}$ lateral. $N C M$, Caudomedial neostriatum; $C M H V$, caudomedial hyperstriatum ventrale; $L 2 a$, subfield of the field L complex.

birds. First, the gene inductions, which serve as the key reference point for these experiments, were defined in awake, unanesthetized birds (Mello et al., 1992, 1995; Mello and Clayton, 1994). Second, the responses we measured occur in higher processing centers of the forebrain, and probably involve both learning and attentional mechanisms. It has been shown that anesthetics have a disruptive effect on auditory responses in diencephalic and telencephalic auditory nuclei, and generally interfere with the learning of behaviors mediated by higher centers (Weinberger, 1982). Thus, we believe that the use of anesthetics may alter or abolish precisely those functional activities that we wish to measure. Throughout these experiments, we monitored the behavioral status of the subjects and observed that zebra finches seem to adapt easily to restraint in a darkened room. We saw no evidence that any aspect of our procedure provoked excessive distress or discomfort. The experiments were performed under a protocol approved by the Ohio State University Institutional Laboratory Animal Care and Use Committee.

Animals and surgical procedures. Adult male zebra finches (Taeniopygia guttata; at least $120 \mathrm{~d}$ in age; $n=26$ ) were bred and raised in Dr. Volman's aviary at the Ohio State University. Before each recording experiment, a subject was anesthetized with $3-4 \mathrm{ml} / \mathrm{kg}$ of a pentobarbital/ chloral hydrate cocktail similar in composition to Equithesin. A portion of the upper skull layer was removed, and a stainless-steel head post was attached to the skull at specific stereotaxic coordinates with dental cement (Grip Cement, L. Caulk Co.). Each bird was visually monitored until it regained consciousness and was able to eat, and then allowed to recover for at least $40 \mathrm{hr}$ before the first recording session.

All of the electrophysiological recordings were conducted in awake, unanesthetized animals. Each subject was suspended in a cloth jacket underneath a custom stereotaxic apparatus (H. Adams, Caltech Central Engineering). NCM was located by its stereotaxic coordinates, and a small hole was opened in the inner skull layer. In some birds, a small slit was made in the dura. Microelectrodes (glass-coated platinum/iridium, of our own manufacture, or lacquer-coated tungsten, FHC, Inc.) were lowered into the brain with a stepping motor-controlled microdrive (H. Adams and M. Walsh Electronics). During the experiment, each bird was isolated the dark, in a large, double-walled anechoic chamber (IAC model 1202).

Neurophysiological experiments were conducted on two separate days with each subject. At the end of the first day of experiments, the opened part of the skull was covered with a layer of silicone grease. The subjects were then returned to their cages and given $\sim 40 \mathrm{hr}$ to rest and recover before their second day of experiments. A typical day's experiment lasted 6-8 hr. While restrained, all subjects were monitored for signs of stress, but typically remained very still throughout the experiment, and were periodically offered water from an eye dropper. Some of the subjects had no access to food, but others were fed ground hard-boiled eggs by hand on an almost hourly basis. When they were returned to their cages after experiments, the birds appeared quite strong, alert, and energetic and began to eat immediately. We recognize that light deprivation and the stress of physical restraint are uncontrolled variables in our experiments. We did not observe in any bird, however, time-dependent effects (such as increasing motion artifacts or reduced responsiveness to stimuli in later trials) that would suggest that these factors were of significant influence on our results.

Anatomical analysis. Small electrolytic lesions $(4-8 \mu \mathrm{A}$ for $4-8 \mathrm{sec})$ were made on one to three penetrations in each animal. Three to four days after the last recording session, the birds were overdosed with anesthesia and perfused with saline followed by $10 \%$ formalin. The brains were frozen, sectioned $(30 \mu \mathrm{m})$ in the sagittal plane, and stained with cresyl violet to recover the lesions and to verify the locations of the recording sites. Sections in which the lesions were visible were drawn by camera lucida and the location of each recording site was determined on the section by referring to the sites of the lesions. Maps representing all recording sites in each bird were digitized by scanning, and the recording sites were plotted at their correct anteroposterior and dorsoventral positions onto one of three standard sections at $0.25,0.45$, or $0.65 \mathrm{~mm}$ lateral to the midline (Fig. 1).

Auditory stimuli. All stimuli were prepared and presented using customdesigned software (C.-Y. Yen, R. A. Mauck, and S. F. Volman) for a Macintosh IIci computer (Volman, 1996). At each unit, the stimulus sets always included two to five conspecific (zebra finch) songs, and also typically included the bird's own song (BOS), one heterospecific song (a white-crowned sparrow song), two to three simple tones, and a white noise burst. These stimuli were presented in a randomly changing order at different sites. Conspecific and heterospecific songs were 2-3 sec long and were followed by $7-8 \mathrm{sec}$ of silence, so that there was one song presentation every $10 \mathrm{sec}$. The computer-generated tone stimuli included frequencies from 500 to $5000 \mathrm{~Hz}$, in $500 \mathrm{~Hz}$ increments, and were $2.13 \mathrm{sec}$ long with $150 \mathrm{msec}$ rise and fall times. The computer-generated white noise burst was $2.05 \mathrm{sec}$ long, with a $40 \mathrm{msec}$ rise and fall time. The presentation rates of the tone and white noise bursts matched that of the conspecific songs. The white crowned sparrow song was used as the heterospecific stimulus because it is similar in length to the zebra finch song but, unlike the finch song, it is composed of pure tonal elements that undergo sometimes rapid and repeated frequency modulations. Responses to two types of modulated tones were also occasionally recorded. Tone "pips" are sets of rapidly repeated bursts of a $1.5 \mathrm{kHz}$ tone; each pip was $80 \mathrm{msec}$ long, with $5 \mathrm{msec}$ rise and fall times, and a $80 \mathrm{msec}$ intertone interval. The other stimulus consisted of a sequence of ascending and descending tones, ranging from $1 \mathrm{kHz}$ to $7 \mathrm{kHz}$, where each tone lasted $150 \mathrm{msec}$ with a $10 \mathrm{msec}$ rise and fall time and $110 \mathrm{msec}$ intertone interval. All tone sequences lasted $\sim 2 \mathrm{sec}$ and were presented at the same rate as the other auditory stimuli (i.e., once every $10 \mathrm{sec}$ ).

Characterization of responses to auditory stimuli in NCM. Neural activity 
was recorded via a single microelectrode in the brain of awake unanesthetized male zebra finches and amplified with an AC amplifier (AM System, Model 1800). Auditory responsive cells in NCM were located and discriminated with a window trigger (BAK Electronics, DIS-1). A randomly ordered set of conspecific and heterospecific songs, tones, and white noise was used to search for units. Some of these songs were used later in the experimental trials, although only as characterization and/or control songs. Systematic recordings of responses to a stimulus set were made wherever a single, responding unit could be isolated ( $n=118$ sites in the 26 birds). The timing of unit action potentials was stored on the computer to an accuracy of $0.1 \mathrm{msec}$.

After a single responding unit was isolated, recordings of responses to various stimulus types were made to determine the unit's response characteristics. Responses to each stimulus were quantified by recording the number of spikes produced by the unit for a period of $10 \mathrm{sec}$, beginning at the presentation onset for each stimulus (Fig. 2). Each stimulus was presented for a block of 10 consecutive repetitions before the next stimulus was played. The summed response to these 10 playbacks was used to create a peristimulus time (PST) histogram, which represented that unit's response for that stimulus. Qualitative discriminations in response characteristics can be identified from the PST histograms (Figs. 2, 3).

Quantitative comparisons of responses to different stimuli (Fig. 4) were based on the mean spike frequency (spikes per second) during 10 consecutive presentations of each stimulus. To control for differences in the level of spontaneous activity and to limit the influence of one or a few very active units, a response value was calculated by subtracting the unit's spontaneous activity (defined as the mean spike frequency generated in the last second of the $10 \mathrm{sec}$ recording interval) from the spike frequency generated during the stimulus presentation, and then dividing this value by the sum of the unit's mean spike frequency generated during the stimulus presentation plus the mean spike frequency during the spontaneous activity. This results in an index constrained between \pm 1 , where values $>0$ indicate net excitation and values $<0$ indicate net inhibition.

We compared response latencies of NCM neurons with those in high vocal center (HVC) by their responses to a white-noise burst of $2 \mathrm{sec}$ duration with a $40 \mathrm{msec}$ rise time. Only those units that produced a clear onset response to this stimulus within the first $40 \mathrm{msec}$ were used for analysis. To calculate latency to an accuracy of $1 \mathrm{msec}$, we counted the number of action potentials in a sliding $4 \mathrm{msec}$ bin, incremented by 1 msec. The neuron was considered to have produced a response when its firing rate was twice the spontaneous level, and it persisted at this level for at least $8 \mathrm{msec}$. Because of the long rise time of the stimulus, these data produce a measure of only the relative latencies in NCM and HVC. It should also be noted that the HVC responses were recorded in anesthetized animals (Volman, 1996), whereas those in NCM were recorded in awake animals.

Analysis of response modulation. Trial by trial comparisons of the responses to 10 consecutive stimulus presentations were made for conspecific song ( $n=118$ units), BOS $(n=50)$, heterospecific song $(n=35)$, tones $(n=37)$, and white noise bursts $(n=36)$. Each presentation lasted $10 \mathrm{sec}$, including the period of silence separating one stimulus from another (see above). When consecutive blocks of either the same or different stimuli were presented (Figs. 5, 8), there was an additional interstimulus interval of $\sim 10$ sec between each block of 10 presentations. For a given stimulus in a given unit, the magnitude of each consecutive response (spikes per second during stimulus presentation) was normalized to the response by that unit to the first presentation of the same stimulus. For conspecific songs, where responses to more than one song were recorded from each unit, a mean response by that unit to all of the conspecific songs presented to it was first calculated, and the trial-by-trial values were then normalized as for other stimuli. Spontaneous rates were also normalized to the initial response elicited during song presentation and are presented in the figures for comparison.

To measure changes occurring with extended $(>10)$ repetitions, three different arbitrarily chosen conspecific songs were used as control songs and were first presented for 10 consecutive repetitions each. Then, another arbitrarily chosen conspecific song was used as a training song and was presented for 1, 10, or 20 blocks of 10 trials each (as described in previous paragraph), with a cumulative duration of $\sim 2,17$, or $34 \mathrm{~min}$, respectively. After the extended repetition of the training song, the control songs were presented again for another 10 consecutive presentations and were then followed by another 10 consecutive presentations of the training song (Fig. 8). Such extended repetition experiments were limited to two per day to decrease the chance of a bird becoming habituated to the experimental paradigm. Each experiment in the same bird made use of songs that were completely novel to that bird. These experiments were conducted at $n=8$ units, where training lasted for 10 presentations, at $n=11$ units, where training lasted for 100 presentations, and at $n=12$ units, where training lasted for 200 presentations.

Statistical methods. Mean data for all presentations of a given stimulus are represented graphically in the figures. Not all units were presented with the same set of stimuli, and so to evaluate the statistical significance of differences in the response to two different stimuli (Fig. 4), we used paired $t$ tests to analyze the subset of units that received both stimuli. In all statistical analyses, probability levels of below 0.05 were considered necessary to demonstrate significance. Differences among the responses to repetitions of a single stimulus or stimulus type (Figs. 6-9) were evaluated using repeated-measures ANOVA (RMA) and post hoc analysis (Tukey's test). Population nomality (Fig. 6B) was assessed with the D'Agostino-Pearson $K^{2}$ test.

\section{RESULTS}

\section{Diverse electrophysiological responses to song presentation}

NCM is a relatively broad area that does not have well defined cytoarchitectonic borders on all sides, nor does it have a clearly organized internal topography (Mello and Clayton, 1994). Previous evidence suggested that cells in NCM would fire in response to complex auditory stimuli (Bonke et al., 1979; Saini and Leppelsack, 1981; Müller and Leppelsack, 1985), but the stimulus selectivity of their responses was unknown. We began with an exploratory approach, therefore, and presented various auditory stimuli to awake restrained adult male zebra finches, and ultimately recorded single unit responses at a total of 129 units scattered throughout the general area previously defined by maximal gene response to song (Fig. 1). In addition to NCM, this area also includes caudomedial portions of the hyperstriatum ventrale (CMHV). In this report, we focus exclusively on the sites within $\operatorname{NCM}(n=118)$, although the qualitative properties of sites in CMHV appeared to be similar. In every portion of NCM studied, the vast majority of cells changed their firing rate in response to one or more types of auditory stimuli, and most responded to a broad range of stimuli, including simple tones, white noise, and birdsong. In response to tones or noise, the cells typically showed excitation during stimulus onset followed by a gradual decline in firing as the stimulus was sustained, and a poststimulus inhibition (although some cells responded to stimulus offset with a brief excitation). Cells that responded to tones often showed complex frequency sensitivities with multiple excitatory and inhibitory frequency ranges. We also observed that units in NCM started their response to white noise bursts by $18 \pm 1.0 \mathrm{msec}$ after stimulus onset; in comparison, units in HVC did not fire until $22 \pm 1.3$ msec ( $p=0.021$; Student's $t$ test, $n=31$ units from each nucleus).

Nearly every unit studied responded to conspecific songs with some degree of excitation over its mean rate of spontaneous firing; however, units varied greatly in their patterns of firing relative to the structure of a song stimulus. This diversity is illustrated in Figure 2, in which we compare the responses of three different units to two different conspecific songs. The first unit responded to both songs as a whole, with essentially tonic activation, continuing even during pauses within the song (Fig. $2 A, B$ ). Nevertheless, some structure in the firing pattern can be seen (the first half of the song in Fig. 2A, for example, elicited more intense firing than the second half). The second unit showed tight synchronization to the internal rhythm of the song (Fig. $2 C, D$ ); firing to each acoustic element, but not firing during intervals of silence between song elements. This unit also showed an increased response to certain components of specific songs, including the final three repeated syllables of song 1 (Fig. $2 C$ ) and the introductory 

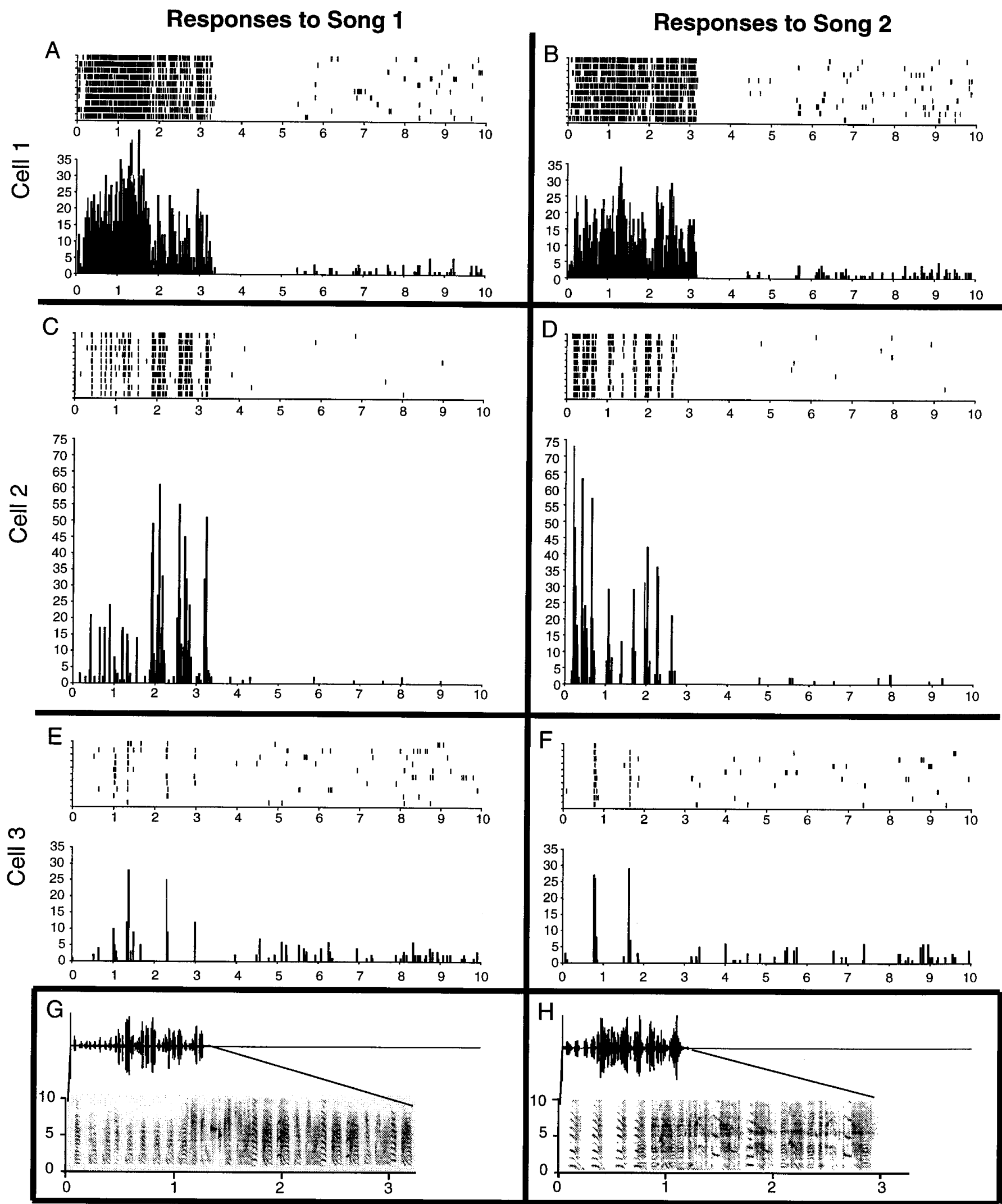

Figure 2. Diversity in the response to songs by single units in NCM. $A-F$, Responses to the same two songs by three different neurons. The responses of each cell to the two songs are aligned side by side $(A, B ; C, D ; E, F)$. Each panel shows a raster plot (top) and a peristimulus histogram (bottom, 30 msec bin width) of spikes recorded from a single unit during 10 repetitions of the song stimulus indicated in the column heading. $G, H$, Amplitude waveform (top) and frequency spectrogram (bottom) of the two song stimuli used ( $G$, song $1 ; H$, song 2$)$. The song waveforms are shown aligned with the unit responses in $A-F$, whereas the time scale of the spectrograms has been expanded for clarity. 

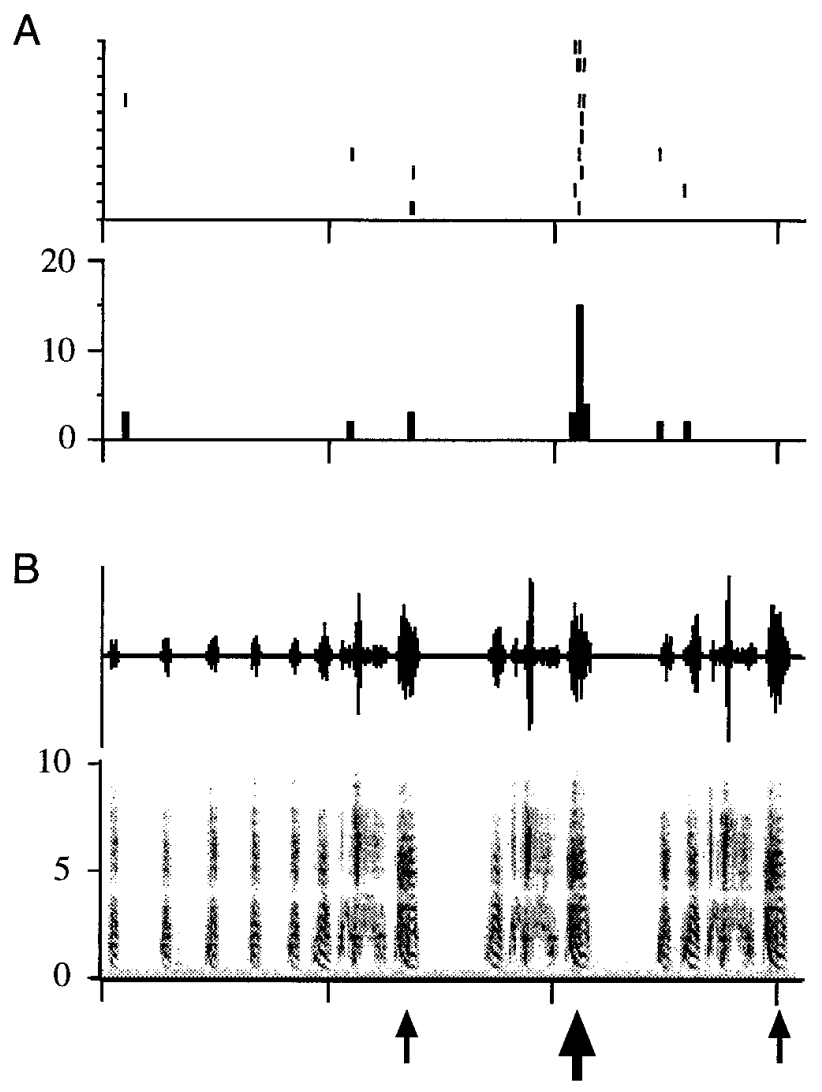

Figure 3. Differential response to the same acoustic element in different contexts. A, Raster plot (top) and peristimulus histogram (bottom) of the response of a single cell to the song stimulus shown in $B$. $B$, Amplitude (top) and frequency (bottom) profile of song stimulus, both aligned temporally with the responses shown in A. Arrows $(B)$ indicate three occurrences of the same acoustic element in this song.

notes of song 2 (Fig. 2D). The third unit displayed an even greater discrimination for specific song elements, and fired only to one or a few syllables in either of the two test songs (Fig. 2E,F). Another example of a highly selective unit is shown in Figure 3. This unit fired very specifically to a single component in the song stimulus (thick arrow). Spectral analysis showed that an apparently identical acoustic element is present two other times within the song (thin arrows), yet the unit showed no response to this element in these other specific contexts.

\section{Quantitative analysis of stimulus selectivity}

In previous studies of gene responses in NCM, conspecific songs were found to elicit more gene expression than did heterospecific songs, and tone stimuli did not cause any detectable gene expression (Mello et al., 1992). To determine whether this selectivity in genomic activation could be explained by differences in the magnitude of electrophysiological activation of units in NCM, we set out to quantitate the relative response of units in NCM to different auditory stimuli. We found that units varied over a 30 -fold range in the absolute rate of spike production, and so to avoid overly biasing our quantitative measurements toward units with high firing rates, we report on data only from well isolated single units and normalize these data to a combination of the spontaneous rate and response magnitude of each cell (see Materials and Methods).

With this approach, we observed that the population of units in NCM showed an excitatory response to birdsong (mean index for
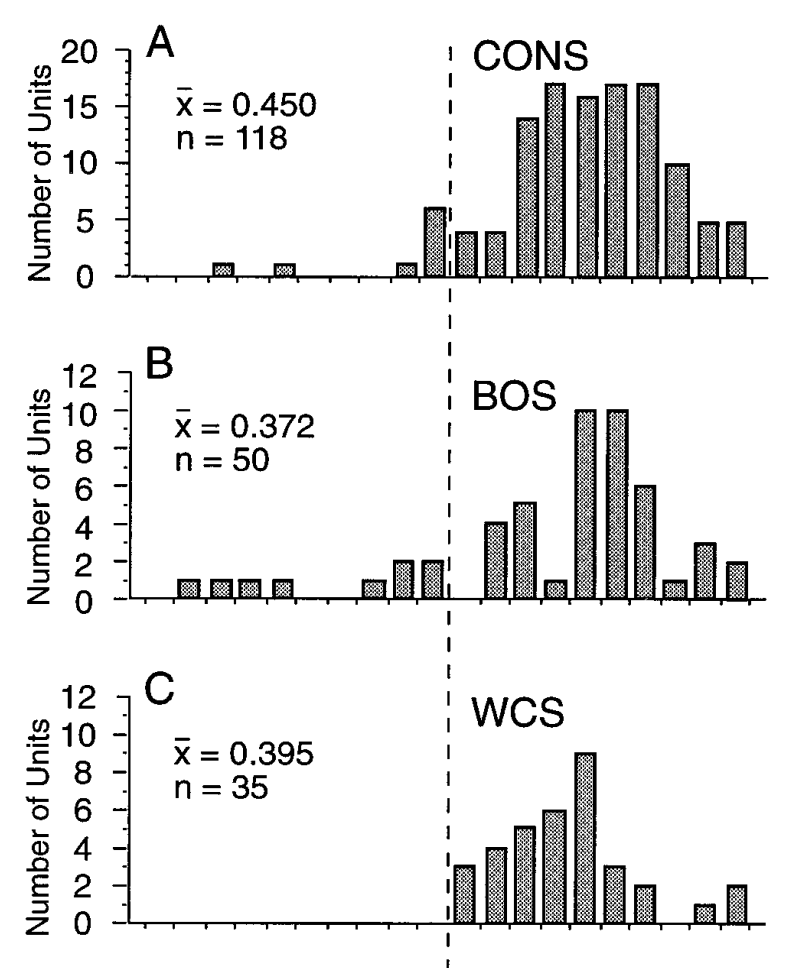

1

BOS
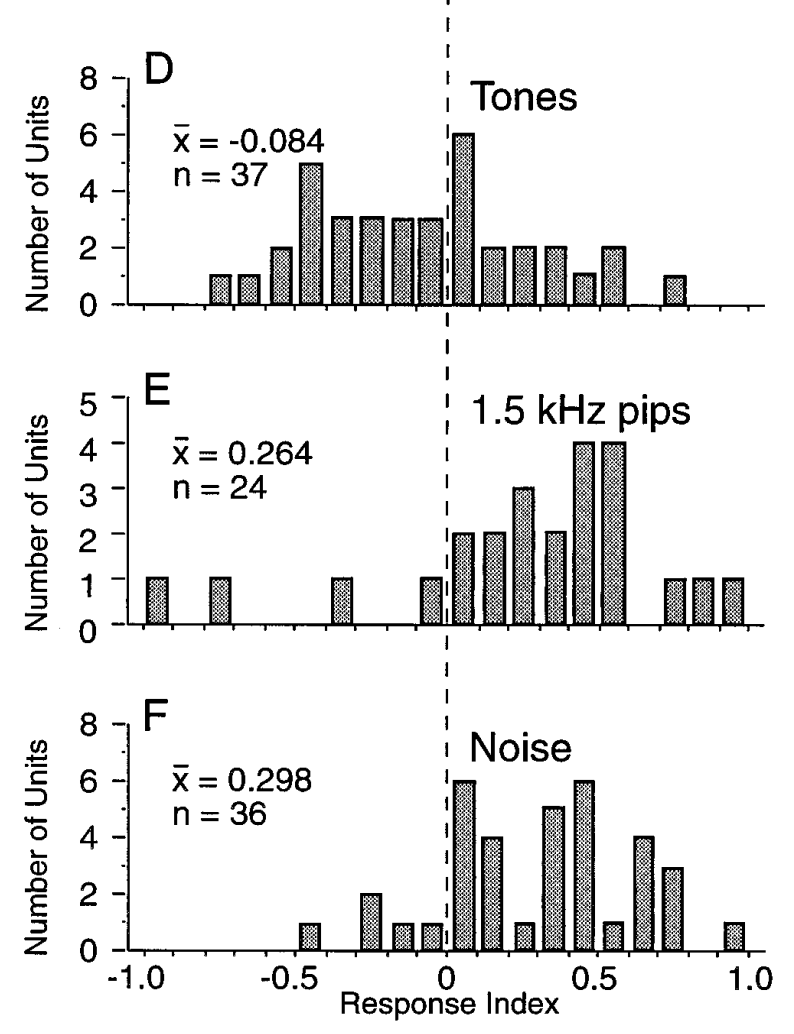

Figure 4. Distributions of response magnitudes to various stimuli. The histograms show the number of units ( $y$-axis) plotted against the normalized index of their rate of firing ( $x$-axis) (see Materials and Methods) during 10 presentations of $A$, conspecific song $(C O N S) ; B$, bird's own song $(B O S) ; C$, white crowned sparrow song $(W C S) ; D$, pure tones (for most cells, several frequencies from $500-5000 \mathrm{~Hz}$ were tested separately and the mean of all responses is plotted here); $E, 1.5 \mathrm{kHz}$ tone pips (see text); and $F$, white noise bursts lasting $2 \mathrm{sec}$ (Noise). Positive values of the index, to the right of the dashed line, indicate a net increase in firing during stimulus presentation, and negative values indicate a net decrease, relative to spontaneous activity. The mean of the response index and the number of units included in each analysis are shown in each panel. 

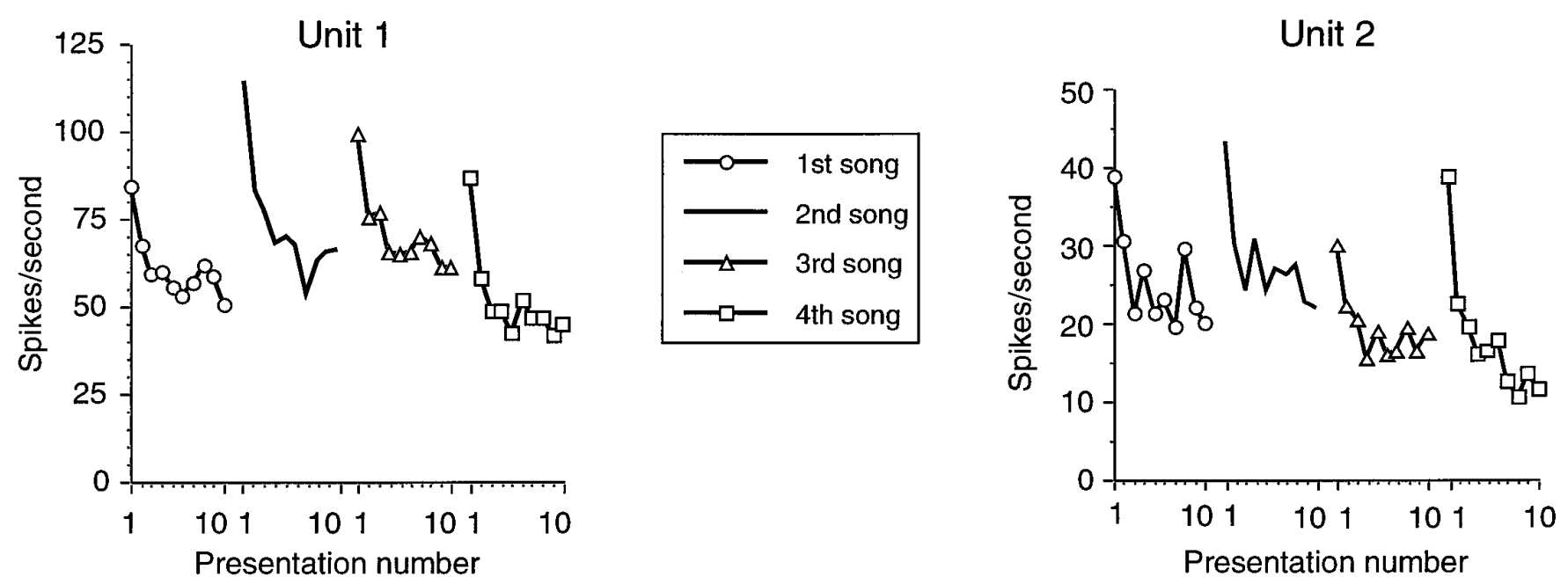

Figure 5. Mean firing rates in response to repeated songs by two different single units. The mean rate of firing for each trial is plotted for two different units, during consecutive presentation of eight different songs, 10 trials each. Raw spike rates (not normalized) are shown. Here and in Figure 8, the placement of the trials along the abscissa does not reflect the exact timing of these events (see Materials and Methods for details about the timing of stimuli within and between blocks of trials).

all song types $+0.41 \pm 0.040)$, with no significant difference by paired $t$ tests in the mean magnitude of the responses to the bird's own song, other conspecific songs, and heterospecific song (Fig. 4) (see Materials and Methods for statistical tests). In contrast to the excitatory responses to songs, the mean response to various sustained pure tones ( $2 \mathrm{sec}$ duration) was inhibitory (Fig. 4, mean index for all tones tested $=-0.084 \pm 0.061 ; p<0.001 \mathrm{vs}$ conspecific song). This included frequencies commonly represented in zebra finch songs: a $1.5 \mathrm{kHz}$ tone, for example, was strongly inhibitory (index $=-0.245 \pm 0.082$, data not shown). When we presented a $1.5 \mathrm{kHz}$ tone, however, as a rapid series of short pips ( $80 \mathrm{msec}$ on, $80 \mathrm{msec}$ off per cycle, for a total overall duration of $2 \mathrm{sec}$ ), the population response became strongly excitatory (Fig. 4) (mean index of response $+0.264 \pm 0.092$, approaching, although not quite equaling, the level seen for songs, $p<0.01$ vs conspecific song). We also observed a strong excitatory response to a $2 \mathrm{sec}$ sequence of tone pips of different frequencies presented in an ascending-descending sequence $(+0.327 \pm 0.092$, data not shown). Thus, pure tones may cause either inhibition or excitation, depending on the temporal organization of the stimulus. Finally, we observed that 2 sec pulses of white noise resulted in a large excitatory response, only slightly less than the response to song (Fig. 4) (index $+0.298 \pm 0.055 ; p<0.005$, noise vs conspecific song).

\section{Rapid modulation of responses during stimulus repetition}

To determine whether units in NCM alter their electrophysiological activity in a way that predicts or follows changes in genomic activity, we examined the responses of single units to repeated presentations of the same song. In contrast to the comparatively slow time course of change in gene responses (Mello and Clayton, 1994; Mello et al., 1995), we found that electrophysiological responses to song not only changed with stimulus repetition, but they changed immediately and dramatically after the first stimulus presentation. As an example, Figure 5 shows the absolute spike rates during the stimulus measured in two single units to sequential presentations of four songs (10 trials per song, different set of songs for each neuron). For both of these units, the response was highest during the first trial of each new song stimulus, but then the firing rate declined sharply for the second trial and remained low for subsequent trials. Changing the song stimulus, however, had the effect of resetting the firing rate to the higher initial level.

To characterize the time course of this changing response in the population of cells in NCM as a whole, various conspecific songs were presented as in Figure 5 (10 trials per song). Single unit response data were collected, and a trial-by-trial time course of the response in the population to all songs was calculated as follows. First, for each unit, the mean response for all songs tested was calculated at each trial (1-10). Then, a normalized time course for the response of each unit was established, by expressing each consecutive response as a percentage of the mean response of each unit at trial 1 . The data for all the units $(n=118)$ were then combined to establish a time course for the whole population (Fig. $6 A$ ). Overall, responses in NCM declined to $\sim 70 \%$ of initial firing rates by the tenth repetition ( $p<0.001, \mathrm{RMA})$. This change in firing rate was most evident between the first and second presentations (mean difference $=15.3 \% \pm 2.21 \% \mathrm{SE}$; by Tukey's test the first presentation was different from each subsequent one, $p<0.001$; presentation 2 was different from presentations 4-10, $p<0.01$; and all other responses were not significantly different). To assess whether this change in response is a uniform property of all units in NCM, we constructed the histogram shown in Figure $6 B$, which shows the difference in response intensity between the first and second presentations in the population of units. Units in NCM show a normal distribution with regard to the magnitude of their change in response ( $p>0.97$, D'Agostino-Pearson $\mathrm{K}^{2}$ test), and we see no evidence of discrete subpopulations that differ in this response property.

When other stimulus types were analyzed for their abilities to induce this rapid modulation, an intriguing pattern emerged. Both BOS and heterospecific song (white-crowned sparrow) induced a modulation very similar to conspecific song (Fig. 7), with a high initial response followed by a sharp decline. In contrast, neither bursts of white noise nor the longer tonal stimuli induced a significant modulation of the response ( $p>0.50$, RMA), although in both cases a small apparent decline in firing rate from the first to the second presentation is evident in the data of Figure 7. Thus, stimuli that induce gene expression (birdsongs) induce a 
A.

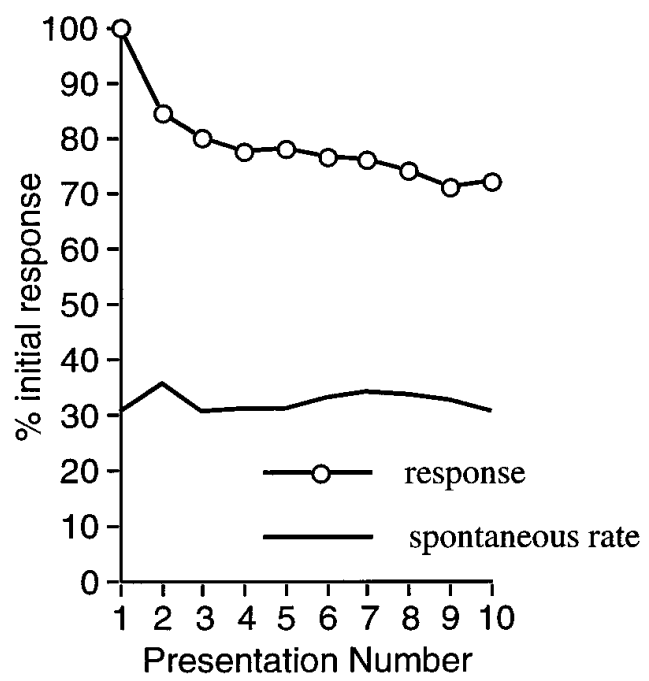

B.

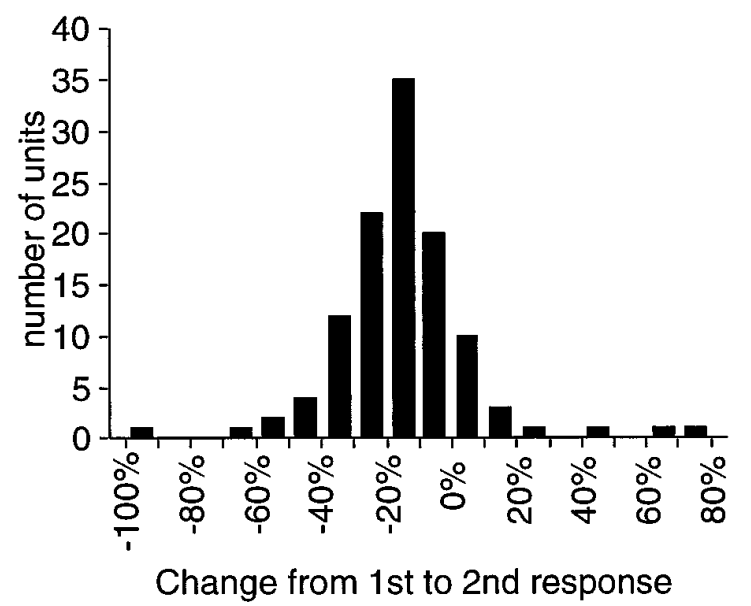

Figure 6. Mean firing rates for the population's response to repeated conspecific song. $A$, Mean of every unit's $(n=118)$ trial by trial responses to conspecific songs. The greatest rate of change occurs between the first and second song presentations, declining $15.3 \% \pm 2.21 \%$. B , Population distribution of initial change in response to repeated conspecific songs. The extent of change in the mean magnitude of responses between the first and second song presentations is distributed normally around the mean.

rapid modulation of firing rate, whereas stimuli that induce little or no expression (tones and noise) seem to induce little or no response modulation.

\section{Loss of response modulation after stimulus repetition}

Studies of the immediate early gene response showed that extended repetition of a single song eventually led to a selective and persistent extinction of the genomic response to that particular song (Mello et al., 1995). To determine whether repeated presentations of one song would cause a similar change in the electrophysiological response of single neurons, we recorded the initial responses to 10 presentations of several control songs and then "trained" the neurons with continued repetition of one song. After training, responses to 10 additional presentations of the same control and training songs were recorded. The specificity of any change in a neuron's response to the training song was
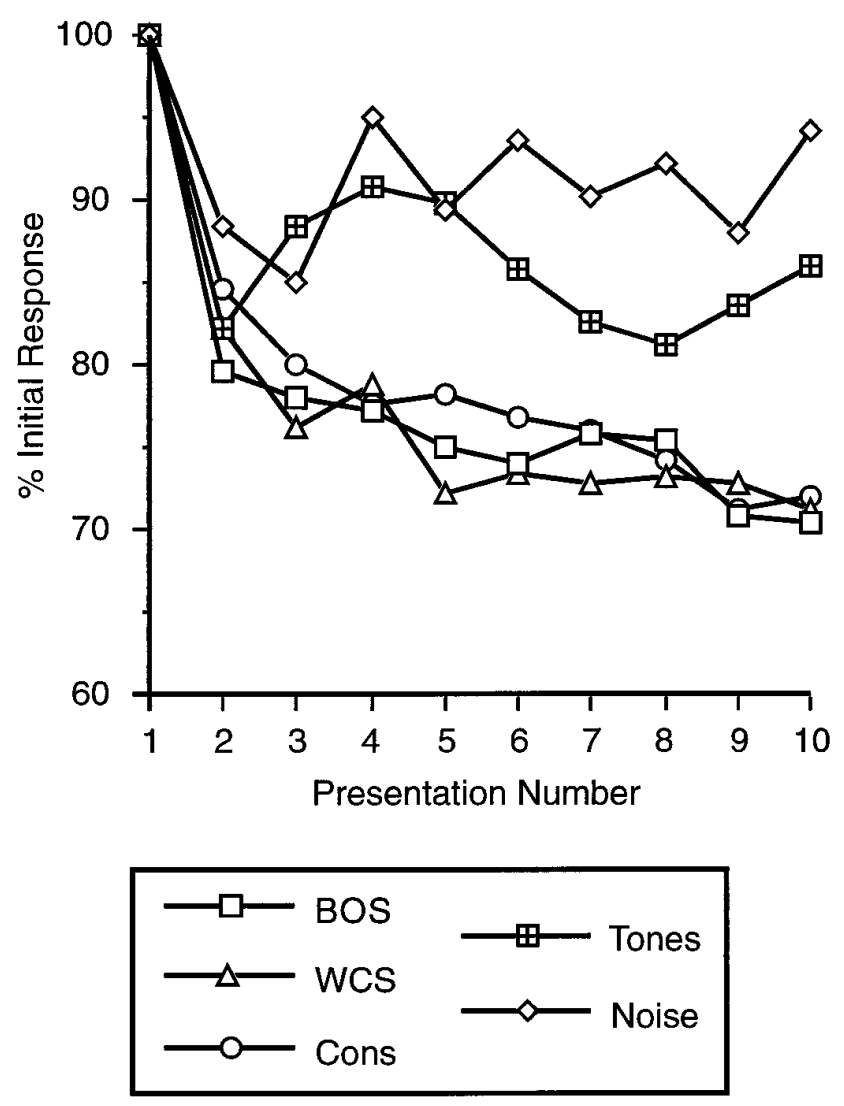

Figure 7. Analysis of response modulation to other repeated auditory stimuli. Trial by trial responses are shown (mean of all single units tested) for BOS $(n=50), \operatorname{WCS}(n=35)$, long tones (Tones; $n=37)$, and white noise bursts (Noise, $n=36$ ); data for conspecific (Cons) songs are repeated here from Figure 6 for comparison. All three types of song stimuli (BOS, WCS, and Cons) elicited similar rapid and persistent response modulations over 10 consecutive presentations. In contrast, there was no significant modulation of the response to repeated tones and white noise $(p>0.50$, RMA).

evaluated by considering whether the response to the control songs also changed. As a simple indicator of the persistence of any changes, we noted whether the post-training presentations of the control stimuli could reset the response to the training song to its pretraining level. The effects of this training procedure are illustrated in Figure 8 for a population of single units $(n=12)$, where the training song was repeated in each case for a total of 200 trials over an elapsed time of $\sim 34 \mathrm{~min}$. The response for each presentation is shown as a percentage of the response to the first presentation of the same stimulus before training.

The initial responses to 10 presentations of the control and training songs, shown at the left side of Figure 8, indicate that the population of units studied in this experiment had the same pattern of dynamic modulation seen in individual units (Fig. 5A), with a high rate of activity during the first presentation of each song followed by an immediate decrease in firing during subsequent presentations. These 12 units had a similar distribution of initial response modulations as observed in the larger population of units characterized in Figure $6 \mathrm{~B}$, with a mean decline of $21.1 \%$ $( \pm 3.8 \%)$ from the first to the second presentation. During the extended repetition of the training song, the spike rate continued to decline slowly throughout the first 20-30 presentations but then stabilized at a level of $\sim 60 \%$ of the initial response, where it 


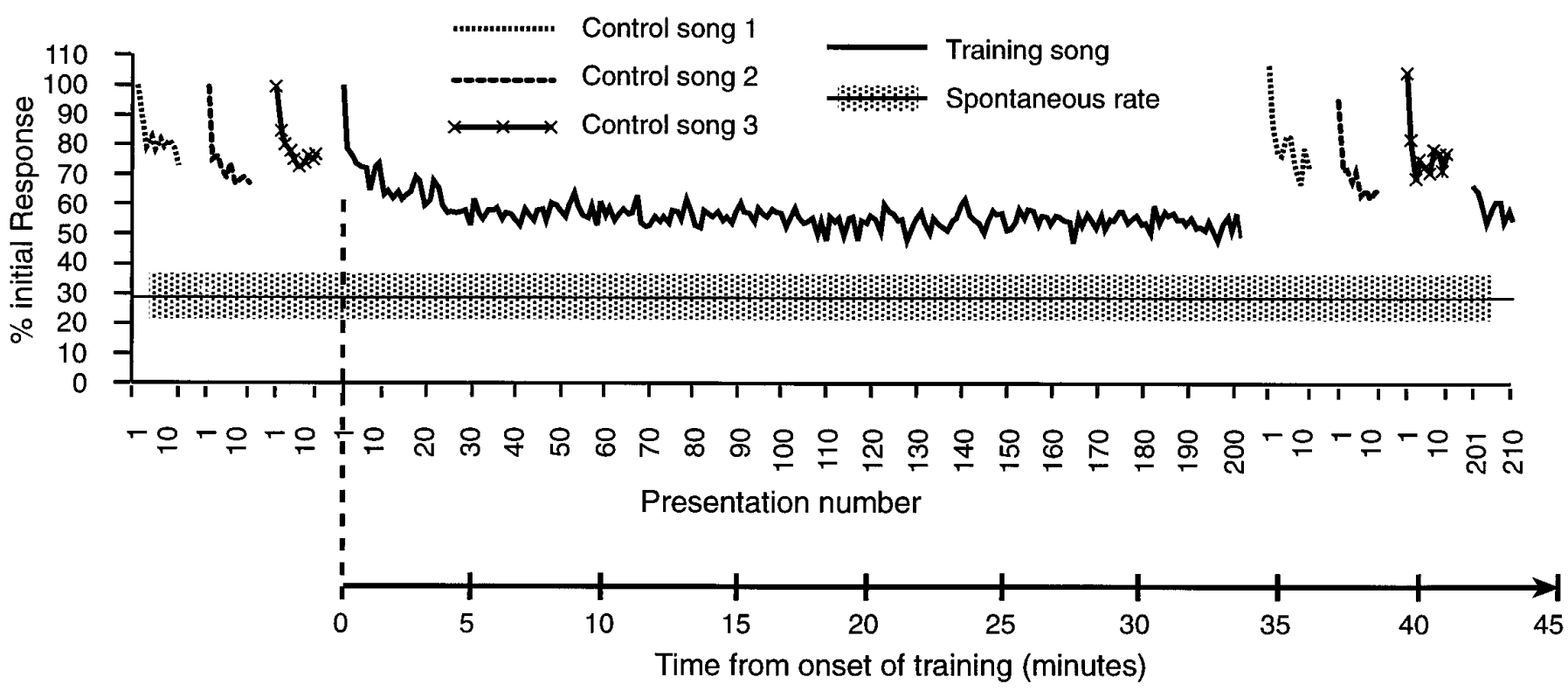

Figure 8. Effect of prolonged exposure to one song on responses by NCM single units ( $n=12$ units in 8 birds). Three conspecific songs (control songs) were played for 10 consecutive repetitions each, before and after 200 consecutive repetitions of a fourth (training) song presented as 20 consecutive blocks of 10 trials. The response to another 10 presentations of the training song was then reassessed, after the last block of control songs. The elapsed time of the training is shown on the timeline at the bottom (for clarity, the interval between control song blocks is increased in this figure; see Materials and Methods for details of timing). Each presentation of the control songs, and the first presentation of the training song, resulted in a rapidly modulated response, similar to Figure 6 . The first introduction of the training song also caused a rapidly modulated response, but unlike the control songs, the subsequent reintroduction of the training song did not result in a significant modulation.

remained to the end of the 200 trials. In contrast, the responses to 10 presentations of the various control songs, when retested after 200 repetitions of the training song, were not significantly reduced in mean magnitude from their pretraining levels (for each control song: $p>0.50$, paired $t$ test), and they continued to show a significant pattern of rapid modulation $(p<0.05$ RMA across the 10 trials for each set of control songs, and in each case, Tukey's test revealed significant differences only between trial 1 and each of trials 2-10).

The responses to the final 10 presentations of the training song, however, differed markedly from the pretraining responses after interruption by the control songs. Firing resumed at a reduced level similar to the rate reached at the end of the 200 training trials ( $p>0.10$, paired $t$ test on mean of last 10 training presentations vs the 10 post-training presentations), and there was no initial sharp modulation of firing rate. The mean decline in the response from the first to the second post-training presentation was now only $2.2 \%( \pm 7.0 \%)$, and there was no significant difference across the responses to these final 10 trials (RMA, $p>0.20$ ). This loss of modulation was evident in 10 of the 12 units tested (data not shown). These results document the appearance of a change in the electrophysiological behavior of single units in NCM that is both stimulus-specific and resistant to interference by other stimuli. They do not indicate, however, that NCM units undergo a major change in their mean rate of firing averaged over time, because the difference is mostly restricted to the first few presentations of the stimulus, occurring within the first minutes of stimulation. Neurons continued to fire in response to the training song at a rate that was approximately twice as high as their rate of spontaneous activity, even after $0.5 \mathrm{hr}$ of continuous stimulus presentation.

A final set of experiments (Fig. 9) was conducted to estimate the minimum number of stimulus repetitions necessary to achieve this stable elimination of response modulation. For reference, Figure $9 C$ replots data from Figure 8 (training for 200 repetitions), showing the modulated pretraining response versus the reduced and relatively flat post-training response to the repeated song, measured after the interruption of the control stimuli. The top panel (Fig. 9A) shows what happens when the response to a song is retested after the interruption of control stimuli, but without any additional training repetitions beyond the initial 10 trials used to measure the pretraining response. In this case, response modulation is still evident: the response to the first presentation is significantly greater than subsequent responses ( $p<0.001$, Tukey's test). The middle panel (Fig. 9B) shows an intermediate level of training, where one song was repeated for 100 trials. Here, again, some degree of response modulation is evident after the interruption of the control songs. Using the difference between the first and second trials as an index of response modulation, the units in all three experiments (Fig. 9) showed a mean decline of $21-24 \%$ before training. After 10 previous training trials, the response modulation was still $21.2 \%$ $( \pm 4.51 \%)$, whereas after 100 training trials it was $13.1 \%( \pm$ $4.67 \%$ ), and after 200 training trials it was only $2.2 \%( \pm 6.94 \%)$. This suggests that training for more than 100 trials $(17 \mathrm{~min})$ and perhaps as many as 200 trials (34 min) is necessary to establish a persistent loss of response modulation to a particular stimulus, although we note that a small decline in the mean firing rate may persist after as few as 10 training trials (Fig. 9A).

\section{DISCUSSION}

Here we described the electrophysiological firing patterns of individual neurons in NCM, a region of the avian telencephalon, which by its connectivity and anatomical position may represent an analog of the mammalian secondary sensory or association cortex (Mello and Clayton, 1994; Vates et al., 1996). Our purpose 

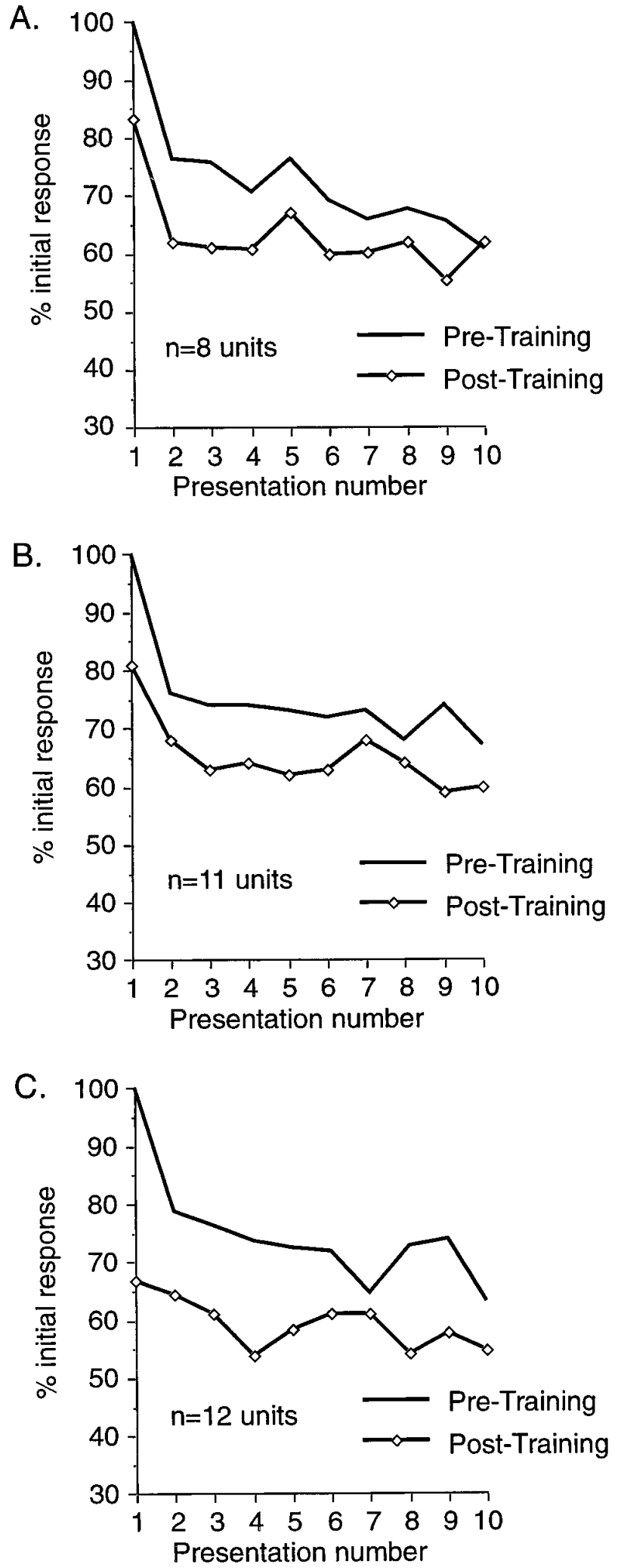

Figure 9. Responses to the same song before and after different durations of training. $A$, Control paradigm: training with 10 consecutive song presentations. $B$, Test paradigm 1: training with 100 consecutive song presentations. $C$, Test paradigm 2: training with 200 consecutive song presentations (data from Fig. 8). Response modulation decreases slightly after training with 100 consecutive presentations of conspecific song and is completely abolished after 200 consecutive conspecific song presentations. was to gain insight into the function of NCM and its dynamic nuclear responses to birdsong (Mello et al., 1992, 1995; Mello and Clayton, 1994; Nastiuk et al., 1994). We found that NCM neurons fired most actively in response to complex auditory stimuli and especially birdsongs, a result consistent with other physiological studies (Bonke et al., 1979; Scheich et al., 1979; Saini and Leppelsack, 1981; Müller and Leppelsack, 1985; Müller and Scheich, 1985; Chew et al., 1995, 1996). Individual neurons displayed no obvious selectivity for particular songs or song types and continued to respond even after extended repetition of a stimulus. With each new introduction of a song, a brief modulation in firing was observed, but a song that had recently been repeated many times no longer produced such modulation. These observations imply that NCM may function to process complex auditory information, but are inconsistent with a role for NCM as a site at which such information is stored in the form of long-term changes in firing rates. To account for the changing genomic activity observed in NCM during song repetition, we propose a model in which (1) nuclear responses are modulated by afferent circuits that are extrinsic to the primary auditory inputs of NCM, and (2) their purpose is to modulate the efferent functions of NCM.

\section{Function of NCM in song perception and memory}

Each NCM neuron fired with equal intensity in response to a diversity of stimuli (Figs. 2-5). The one song most familiar to the bird (the bird's own song) caused a response of similar overall magnitude to other conspecific songs (Fig. 4). Thus, the instantaneous activity of an NCM neuron cannot alone indicate or represent a specific stimulus. Nevertheless, the response of each neuron to song had a characteristic temporal structure that varied in an idiosyncratic way in the population (Fig. 2), and it therefore seems possible that each song may generate a unique signature of dynamic activity across a population of neurons within NCM. Thus, we suggest that NCM can act as a processing center for the momentary representation of complex auditory information, but not necessarily as a storage site for specific song-related memories. These representations may be projected to other brain regions (Vates et al., 1996) for various purposes, including the recognition, memorization and storage of specific song patterns, and may contribute to the abilities of adult songbirds to monitor the comings and goings of other birds and respond with appropriate behaviors (Catchpole, 1982; Kroodsma and Byers, 1991; Wiley et al., 1991; Beecher et al., 1996).

The potential relationship between NCM and song nucleus HVC seems especially worthy of further characterization. Units in NCM may project to HVC (Fortune and Margoliash, 1995; Vates et al., 1996), and our latency data here allow the possibility that NCM provides a major excitatory input to HVC. Some neurons in HVC show highly specific electrophysiological responses to song, but how this specificity emerges is not known. Here we observed responses in a subset of NCM units that seemed to exhibit a selectivity for context, a property that seems similar to the pattern of "temporal and combination selectivity" described in HVC (Margoliash, 1983; Margoliash and Fortune, 1992; Volman, 1993; Sutter and Margoliash, 1994). A rigorous analysis of the acoustic and context sensitivities in NCM might provide insight into neural mechanisms responsible for the specificities observed in HVC.

\section{Stimulus-specific response modulation}

Neurons in NCM initially responded to all songs (including the bird's own song) with a rapid modulation in their firing rate (Fig. 7). One interpretation of this result is that the afferent synapses 
activated by a particular song rapidly habituated with stimulus repetition (Chew et al., 1995, 1996). The initial change, however, in the response to one song seemed to have no influence on the response of a neuron to other conspecific songs (Fig. 5). Furthermore, we observed that with sufficient stimulus repetition, the modulation itself eventually ceased, and this change was highly song-specific (Fig. 8). The selectivity of these changes is not readily accounted for by a model based on habituation of primary sensory inputs, which would require distinct subsets of dedicated synapses onto each neuron for each of many different songs, and which therefore presupposes the existence of a set of song-specific inputs from lower auditory centers. Yet the evidence suggests that the inputs of NCM are not likely to be song-specific (Müller and Leppelsack, 1985). Moreover, if NCM neurons did receive songspecific inputs that selectively habituated, why have they not developed song-selective responses by adulthood?

A more plausible interpretation is that the initial response modulation results from the activity of extrinsic circuits, perhaps analogous to modulatory systems studied in mammals (Moratalla et al., 1992; LeDoux, 1993; McGaugh et al., 1993; Campeau and Davis, 1995). Reciprocal connections have been demonstrated between NCM and various other structures (Mello and Clayton, 1994; Vates et al., 1996), and some of these may integrate the population activity within NCM (and perhaps elsewhere) to generate song- and context-specific feedback onto NCM and modulate its excitability. This could allow for the rapid enhancement of signal processing in response to novel contexts, environments, or circumstances. This hypothesis leads to two testable predictions: (1) lesion or pharmacological elimination of appropriate modulatory circuits should result in an unchanging response in NCM to songs when they are first presented and (2) at least some of the brain regions that project back to NCM should show song-selective electrophysiological responses, to provide the basis for the observed song-selective modulation and attenuation in NCM.

\section{Function of gene responses in NCM}

This description of the electrophysiological responses of NCM allows an assessment of the relationship between functional activity in neurons and the "immediate-early" gene response, which has been well described in NCM. Repeated playback of one song for 30-40 min was shown to cause an "all or none" accumulation of zenk or c-jun mRNAs in just under half the neurons in zebra finch NCM (Nastiuk et al., 1994; Mello et al., 1995). In the present study, almost all neurons identified by our search criteria showed some increase in firing during presentation of each and every conspecific song. The magnitude of activation varied substantially and with normal distribution across the population. Assuming that our electrophysiological search criteria were sufficient to identify the full range of response magnitudes in NCM, then gene induction must not always occur in all neurons that are electrophysiologically activated.

In the gene induction studies, different classes of stimuli induced different amounts of zenk mRNA in NCM, apparently by activating different proportions of cells. Conspecific songs induced twice as much zenk as heterospecific (canary) song (Mello et al., 1992) and four times as much as white noise (Mello, 1993). Here, we observed no large difference in either the mean or the population distribution of electrophysiological responses to these classes of stimuli. This last comparison is somewhat tentative, because the stimuli used here were not precisely identical to those used previously and we have not yet formally measured the amount of gene induction they produce, but the combined results are strong evidence that various experiential stimuli can induce similar overall levels of electrophysiological activity in NCM neurons, yet have different effects on gene activity.

Both the electrophysiological and genomic responses changed as a particular stimulus was repeated, and comparison of the nature and time course of these changes may provide insight into the functional relationship(s) between these two types of physiological activity. This comparison is confounded by the fact that mRNA levels reflect the recent history of two different metabolic processes (transcription vs degradation), whereas electrophysiological firing is a measure of the neuron's instantaneous state. Nevertheless, several salient points emerge. First, the initial modulation of electrophysiological firing occurred primarily from the first to the second presentation of a new song $(10 \mathrm{sec})$, whereas zenk mRNA does not even accumulate to detectable levels until $\sim 60$ presentations (10 min) (Mello and Clayton, 1994), with protein levels lagging closely behind (Mello, 1995). Hence, the gene response clearly can have no causal role in the initial modulation of electrophysiological activity. The modulation of firing, however, could have a causal role in gene induction: stimuli that have been repeated $30 \mathrm{~min}$ or more cease to induce the gene response (Mello et al., 1995), and our results here indicate that this change may be anticipated by a loss of the electrophysiological modulation (Fig. 9). Also, stimuli that were poor inducers of the gene response (i.e., white noise and pure tones) failed to elicit the electrophysiological modulation (Fig. 7). Finally, we note that electrophysiological modulation declined on a time course that approximately parallels the accumulation of gene products-in both cases small changes began to emerge after 10-15 min and were fully expressed after $\sim 30 \mathrm{~min}$. This time course is consistent with the widely hypothesized role of gene induction in the consolidation of short-term memories into interference-resistant forms after $\sim 30 \mathrm{~min}$ (Davis and Squire, 1984; Goelet et al., 1986).

We conclude that activation of nuclear responses in NCM must require something other than just depolarization and/or action potential production. The most parsimonious explanation is that gene induction requires activity in inputs carrying modulatory signals related to stimulus context and salience, and these inputs also cause the transient modulation of firing seen when a new song is first introduced in the experimental paradigm. This transient modulation might itself serve as the trigger for gene induction (by raising the firing rate above a key threshold), or it might be a functionally insignificant consequence of the activity of receptors and intracellular messengers responsible for delivering the modulatory signal to the cell nucleus. Because NCM neurons themselves do not seem to undergo major long-term changes in their own response properties, we propose that the primary function of the gene response in NCM may be to consolidate changes in the synaptic outputs of NCM. This is consistent with the presynaptic orientation of a number of proteins that are apparent targets of "immediate early gene" regulation, including major synaptic vesicle-associated proteins (Thiel et al., 1994; Petersohn et al., 1995; Vician et al., 1995), neuropeptides and transmitter synthesizing enzymes (Gizang-Ginsberg and Ziff, 1992; Borsook et al., 1994; Ebert et al., 1994; Guardioladiaz et al., 1994), and proteins associated with axonal structure and outgrowth (Meberg et al., 1993; Pospelov et al., 1994). The testable prediction of this hypothesis is that at least some of the targets of NCM should undergo significant and more lasting changes in their apparent 
stimulus specificities as a result of nuclear activation in NCM. In this model, the neuronal nucleus would integrate signals from multiple inputs onto the cell and then modulate the efficacy of the specific outputs of the neuron, thereby playing a large role in determining how neural circuit function is modified in response to experience.

\section{REFERENCES}

Beecher MD, Stoddard PK, Campbell SE, Horning CL (1996) Repertoire matching between neighbouring song sparrows. Anim Behav 51:917-923.

Bonke D, Scheich H, Langer G (1979) Responsiveness of units in the auditory neostriatum of the guinea fowl (numida meleagris) to speciesspecific calls and synthetic stimuli. 1. Tonotopy and functional zones of field L. J Comp Physiol [A] 132:243-255.

Borsook D, Falkowski O, Rosen H, Comb M, Hyman S (1994) Opioids modulate stress-induced proenkephalin gene expression in the hypothalamus of transgenic mice: a model of endogenous opioid gene regulation by exogenous opioids. J Neurosci 14:7261-7271.

Campeau S, Davis M (1995) Involvement of subcortical and cortical afferents to the lateral nucleus of the amygdala in fear conditioning measured with fear-potentiated startle in rats trained concurrently with auditory and visual conditioned stimuli. J Neurosci 15:2312-2327.

Catchpole CK (1982) The evolution of bird sounds in relation to mating and spacing behaviour. In: Acoustic communication in birds, (Kroodsma DE, Miller EH, ed), pp 297-319. New York: Academic.

Chew SJ, Mello C, Nottebohm F, Jarvis E, Vicario DS (1995) Decrements in auditory responses to a repeated conspecific song are longlasting and require two periods of protein synthesis in the songbird forebrain. Proc Natl Acad Sci USA 92:3406-3410.

Chew SJ, Vicario DS, Nottebohm F (1996) A large-capacity memory system that recognizes calls and songs of individual birds. Proc Natl Acad Sci USA 93:1950-1955.

Davis HP, Squire LR (1984) Protein synthesis and memory: a review. Psychol Bull 96:518-559.

Ebert SN, Balt SL, Hunter JPB, Gashler A, Sukhatme V, Wong DL (1994) EGR-1 activation of rat adrenal phenylethanolamine $N$-methyltransferase gene. J Biol Chem 269:20885-20898.

Fortune ES, Margoliash D (1995) Parallel pathways and convergence onto HVc and adjacent neostriatum of adult zebra finches (Taeniopygia guttata). J Comp Neurol 360:413-441.

Gizang-Ginsberg E, Ziff EB (1992) Fos family members successively occupy the tyrosine hydroxylase gene AP-1 site following NGF or EGF stimulation of PC12 cells and can repress transcription. Mol Endocrinol 8:249-262.

Goelet P, Castelucci V, Schacher S, Kandel E (1986) The long and the short of long-term memory: a molecular framework. Nature 332:419-422.

Guardioladiaz HM, Boswell C, Seasholtz AF (1994) The cAMP responsive element in the corticotropin-releasing hormone gene mediates transcriptional regulation by depolarization. J Biol Chem 269:14784-14791.

Konishi M (1989) Birdsong for neurobiologists. Neuron 3:541-549.

Kroodsma DE, Byers BE (1991) The function(s) of bird song. Am Zool 31:318-328.

LeDoux JE (1993) Emotional memory systems in the brain. Behav Brain Res 58:69-79.

Margoliash D (1983) Acoustic parameters underlying the responses of song-specific neurons in the white-crowned sparrow. J Neurosci 3:1039-1057.

Margoliash D, Fortune ES (1992) Temporal and harmonic combinationsensitive neurons in the zebra finch's HVc. J Neurosci 12:4309-4326.

McGaugh JL, Introini-Collison IB, Cahill LF, Castellano C, Dalmaz C, Parent MB, Williams CL (1993) Neuromodulatory systems and memory storage: role of the amygdala. Behav Brain Res 58:81-90.

Meberg PJ, Gall CM, Routtenberg A (1993) Induction of F1/GAP-43 gene expression in hippocampal granule cells after seizures. Mol Brain Res 17:295-297.

Mello CV (1995) Immuncytochemical analysis of ZENK gene induction by song stimuli in the zebra finch brain. Soc Neurosci Abstr 21:959.
Mello CV (1993) Analysis of immediate early gene expression in the songbird brain following song presentation. Ph.D. thesis. The Rockefeller University.

Mello CV, Clayton DF (1994) Song-induced ZENK gene expression in auditory pathways of songbird brain and its relation to the song control system. J Neurosci 14:6652-6666.

Mello CV, Nottebohm F, Clayton DF (1995) Repeated exposure to one song leads to a rapid and persistent decline in an immediate early gene's response to that song in zebra finch telencephalon. J Neurosci 15:6919-6925.

Mello CV, Vicario DS, Clayton DF (1992) Song presentation induces gene expression in the songbird forebrain. Proc Natl Acad Sci USA 89:6818-6822.

Moratalla R, Robertson H, Graybiel A (1992) Dynamic regulation of NGFI-A (Zif-268, egr-1) gene expression in the striatum. J Neurosci 12:2609-2622.

Müller CM, Leppelsack H (1985) Feature extraction and tonotopic organization in the avian auditory forebrain. Exp Brain Res 59:587-599.

Müller SC, Scheich HP (1985) Functional organization of the avian auditory field L: a comparative 2-deoxyglucose study. J Comp Physiol [A] 156:1-12.

Nastiuk KL, Mello CV, George JM, Clayton DF (1994) Immediate-early gene responses in the avian song control system: cloning and expression analysis of the canary c-jun cDNA. Mol Brain Res 27:299-309.

Nottebohm F, Stokes T, Leonard CM (1976) Central control of song in the canary. J Comp Neurol 165:457-486.

Petersohn D, Schoch S, Brinkmann DR, Thiel G (1995) The human synapsin II gene promoter: possible role for the transcription factors zif268/egr-1, polyoma activator 3, and AP2. J Biol Chem 270:24361-24369.

Pospelov V, Pospelova T, Julien J-P (1994) AP-1 and Krox-24 transcription factors activate the neurofilament light chain gene promoter in P19 embryonal carcinoma cells. Cell Growth Differ 5:187-196.

Saini KD, Leppelsack H-J (1981) Cell types of the auditory caudomedial neostriatum of the starling (Sturnus vulgaris). J Comp Neurol 198:209-229.

Scheich H, Bonke BA, Bonke D, Langner D (1979) Functional organization of some auditory nuclei in the guinea fowl demonstrated by the 2-deoxyglucose technique. Cell Tissue Res 204:17-27.

Stripling R, Volman S, Clayton D (1994) Electrophysiological responses to song presentation in caudomedial neostriatum of zebra finches: links to ZENK gene induction. Soc Neurosci Abstr 20:165.

Stripling R, Volman SF, Clayton DF (1995) Learned song discrimination at the single cell level in zebra finch caudomedial neostriatum (NCM). Soc Neurosci Abstr 21:959.

Sutter ML, Margoliash D (1994) Global synchronous response to autogenous song in zebra finch hvc. J Neurophysiol 72:2105-2123.

Thiel G, Schoch S, Petersohn D (1994) Regulation of synapsin I gene expression by the zinc finger transcription factor Zif268/EGR-1. J Biol Chem 269:15294-15301.

Vates GE, Broome BM, Mello CV, Nottebohm F (1996) Auditory pathways of the caudal telencephalon and their relation to the song system of adult male zebra finches (Taenopygia guttata). J Comp Neurol 366:613-642.

Vician L, Lim IK, Ferguson G, Tocco G, Baudry M, Herschman HR (1995) Synaptotagmin IV is an immediate early gene induced by depolarization in PC12 cells and in brain. Proc Natl Acad Sci USA 92:2164-2168.

Volman SF (1993) Development of neural selectivity for birdsong during vocal learning. J Neurosci 13:4737-4747.

Volman SF (1996) Quantitative assessment of song-selectivity in the zebra finch "high vocal center". J Comp Physiol [A] 178:849-862.

Weinberger NM (1982) Effects of arousal and attention on the auditory system. In: The neural basis of behavior (Beckman AL, ed), pp 63-91. NY: Spectrum.

Wiley R, Tatchwell B, Davis N (1991) Recognition of individual males' songs by female dunnocks: a mechanism increasing the number of copulatory partners and reproductive success. Ethology 88:145-153. 